\title{
Do Community Health Centers Have Contextual Effect on the Risk of Recurrence in Patient with Tuberculosis? A Multilevel Evidence from Surakarta, Central Java
}

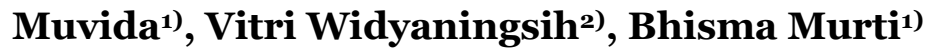 \\ 1)Masters Program in Public Health, Universitas Sebelas Maret \\ ${ }^{2)}$ Faculty of Medicine, Universitas Sebelas Maret
}

Background: Community Health Centers played an important role in tuberculosis control. However, Community Health Centers' contextual effect toward tuberculosis recurrence has not yet been discovered. The study aims to analyze sociodemography and clinical factors of first tuberculosis episode and Community Health Centers' contextual effect toward tuberculosis recurrence. Subjects and Method: It was analytic observational study with case control approach. The study was conducted in the city of Surakarta, Central Java, from December 2019 up to January 2020. Sample collection toward 204 tuberculosis patients who had completed their treatment or were confirmed cured, were conducted by using simple random sampling at individual level and stratified random sampling at community health centers level. The dependent variable was tuberculosis recurrence. The independent variables were family income, level of education, BCG vaccination status, smoking history, initial bacteriological test, weight gain, DM, and COPD. The data were collected through medical record and interview. The data were analyzed by using multilevel multiple logistic regression with Stata 13. Results: In individual level, the preventive factor toward tuberculosis recurrence among other were high income $(\mathrm{OR}=0.24 ; 95 \% \mathrm{CI}=$ 0.06 up to $0.92 ; \mathrm{p}=0.037$ ), high level of education $(\mathrm{OR}=0.18 ; 95 \% \mathrm{CI}=0.04$ up to $0.84 ; \mathrm{p}=$
0.029), BCG vaccination status (OR= $0.11 ; 95 \%$ $\mathrm{CI}=0.02$ up to $0.67 ; \mathrm{p}=0.017)$, and high weight gain $(\mathrm{OR}=0.06 ; 95 \% \mathrm{CI}=0.01$ up to $0.28 ; \mathrm{p}<$ o.001). Meanwhile, the independent predictors toward tuberculosis recurrence $(\mathrm{OR}=7.11 ; 95 \%$ $\mathrm{CI}=1.65$ up to $30.64 ; \mathrm{p}=0.009)$ and diabetes mellitus $(\mathrm{OR}=10.85 ; 95 \% \mathrm{CI}=2.13$ up to 55.29 ; $\mathrm{p}=0.004)$. In the level of Community Health Centers, high ratio between health workers/ tuberculosis patients significantly correlated with lower tuberculosis $(\mathrm{OR}=0.01 ; 95 \% \mathrm{CI}<0.01 \mathrm{up}$ to $0.44 ; \mathrm{p}=0.016$ ). Community health Centers had contextual effect toward tuberculosis recurrence with Intra-Class Correlation (ICC) by $38.67 \%$.

Conclusion: Factors in individual and community health centers level may affect tuberculosis recurrence. Community Health Centers has contextual effect toward tuberculosis recurrent.

Keywords: Tuberculosis recurrence, tuberculosis, predictor, Community Health Center, multilevel analysis

\section{Correspondence: \\ Muvida. Masters Program in Public Health, Universitas Sebelas Maret, Jl. Ir. Sutami No. 36 A, Surakarta 57126, Central Java. Email: muvida- md@gmail.com. Mobile: +6289651450435.}

Cite this as:

Muvida, Widyaningsih V, Murti B (2020). Do Community Health Centers Have Contextual Effect on the Risk of Recurrence in Patient with Tuberculosis? A Multilevel Evidence from Surakarta, Central Java. J Epidemiol Public Healt. 5(1): 66-79. https://doi.org/10.26911/jepublichealth.2020.05.01.07

(c) (1) (2) Journal of Epidemiology and Public Health is licensed under a Creative Commons Attribution-Non Commercial-Share Alike 4.o International License.

\section{BACKGROUND}

Tuberculosis (TB) is still a priority as one of main public health problems. TB tightly competes with human immunodeficiency virus
(HIV) in top ten infectious diseases that cause death worldwide. Prevalence and mortality rate still indicate that global TB elimination is not fully conducted even though 
TB incidences has been decreasing (Sulis et al., 2014).

Based on WHO report in 2017 there have been 10 million new cases globally with 1.6 million mortality rate (WHO, 2018a). Indonesia ranks the third out of 8 top leading countries that contribute in two third new TB cases worldwide after India (27\%) and China (9\%) (WHO, 2018b).

Tuberculosis control effort is often complicated by the recurrence on individuals that have obtained treatment. Indonesian Association of Pulmonologist (2011) reports that tuberculosis recurrence case is tuberculosis patients who obtained tuberculosis treatment before and have been confirmed cured or completed treatment, and later come to get treatment again with positive AFB for sputum test result.

TB recurrence is caused by a lot of factors, whether it is host factor, treatment factor, and environmental factor (Davies and Wallis, 2016; Sotgiu et al., 2016). The external factor whose contribution to recurrence is not yet studied is healthcare provider factor in which TB patients are treated. Tuberculosis control which is a national program requires each healthcare facilities administered by government, including Community Health Centers and hospitals, to provide tuberculosis care and treatment until the patients are confirmed cured or completed treatment (Ministry of Health., 2011).

Several Community Health Centers can make special program in accordance with the condition of respective region or establish a service that beneficial in controlling risk factors of tuberculosis recurrence (Ministry of Health, 2011). Performance of respective Community Health Center can give contribution toward recurrence risk of tuberculosis patients.

Tuberculosis recurrence risk contributed by Community Health Centers indicates that there is likely an occurrence of factors from above individual level, which should be analyzed. The analysis strategy that may be used to meet the needs is multilevel analysis that enables simultaneous examination of group level factors (in this term is Community Health Centers) and individual level (Hox, 2010). Based on the understanding, the authors intended to conduct analysis toward TB recurrence predictors in the city of Surakarta with multilevel approach.

\section{SUBJECTS AND METHOD}

\section{Study Design}

It was an observational analytic study with case control approach. It was conducted in Community Health Centers in the city of Surakarta from December 2019 - January 2020.

\section{Population and Sample}

The source population of the study was all recurrent tuberculosis patients who get medical treatment in Community Health Centers in the city of Surakarta. The study subjects were taken randomly based on data of tuberculosis patients who get treatment in Community health centers by January 2013 - January 2020.

\section{Study Variables}

Dependent variable was tuberculosis recurrent. Independent variables in individual level included family income, level of education, BCG vaccination status, smoking history, initial bacteriological test, weight gain, DM and COPD. Whereas independent variables in Community Health Center level were population coverage, number of TB patients, number of TB officers, ratio between TB patients/ officers, and smoking cessation clinics.

\section{Operational Definition of Variables} Tuberculosis recurrence was tuberculosis patients who have recovered or obtained complete treatment, and later confirmed to suffer from TB again with positive result of Acid-Fast Bacillus (AFB) sputum smear or 
culture. Dichotomous scale with criteria $\mathrm{O}=$ not recurrent; $1=$ recurrent.

Family income was the amount of average income within the last 3 months in one study subject house. It was calculated by summing up the 3 months income and finally was divided by 3 . The continuous data scale was modified into dichotomous to facilitate data analysis with criteria $0=<\operatorname{Rp} 1,800,000 ; 1=\geq R p$ $1,800,000$.

Level of education was the last level of education taken by study subjects. The instrument used was questionnaires. The continuous data scale was modified into dichotomous to facilitate data analysis with criteria $\mathrm{o}=$ Non Elementary School graduates - Junior High School graduates; 1= High School graduates - higher educational level. Smoking history was smoking behavior or habit and or had been smoking in daily life. The instrument used was questionnaires. Dichotomous scale with criteria $\mathrm{O}=$ not smoking; 1 = smoking.

Initial bacteriological test was the result of sputum smear examination or rapid molecular test in the beginning of treatment. The instrument used was AFB or rapid molecular test examination. The data was taken from medical record. Dichotomous scale with criteria $\mathrm{O}=$ negative result of $\mathrm{AFB}$ or rapid molecular test; $1=$ positive result of $\mathrm{AFB}$ or rapid molecular test.

Weight gain the difference of weight in the end and the beginning of treatment. The instrument used was body scales. The data were obtained from medical record. The continuous data scale was modified into dichotomous to facilitate data analysis with criteria $0=$ low ( $<$ mean body weight); $1=$ high ( $\geq$ mean body weight).

Diabetes mellitus was a chronic diseases marked by body failure in regulating glucose level of the body. The instrument was by using fasting blood glucose test. The data were taken obtained from medical record.
Dichotomous scale with criteria $\mathrm{o}=$ Non DM; $1=$ DM.

Chronic Obstructive Pulmonary Diseases was chronic pulmonary diseases marked by obstructed air flow in respiratory tract which was reversible or partially reversible in nature. The instruments used were physical and radiology examination. The data were obtained from medical record. Dichotomous scale with criteria $0=$ Non COPD, $1=$ COPD.

BCG vaccination status was the history of previous BCG vaccination. The instrument used was questionnaires. Dichotomous scale with criteria $0=$ not $B C G$ vaccinated, $1=B C G$ vaccinated.

Population coverage was number of population included in a region served by a Community Health Center. The instrument used was population coverage data of Community Health Center. The continuous data scale was modified into dichotomous to facilitate data analysis with criteria $0=$ low; $1=$ high.

Number of TB patients was the number of tuberculosis patients treated in local Community Health Center within 1 month period. Instrument used was tuberculosis countermeasure data of Community Health Center. The continuous data scale was modified into dichotomous to facilitate data analysis with criteria $0=$ low $;=$ high.

Number of TB control officers was the number of officers involved in tuberculosis control program in a Community Health Center. The instrument used was tuberculosis counter measure data of Community Health Center. The continuous data scale was modified into dichotomous to facilitate data analysis with criteria $0=$ low; $1=$ high .

Ratio of TB officers/ patients was a comparison between the number of TB officers and the number of TB patients in a Community Health Center. The instrument used was tuberculosis countermeasure data of Community Health Center. The continuous 
data scale was modified into dichotomous to facilitate data analysis with criteria $\mathrm{O}=$ low; $1=$ high.

Smoking Cessation Clinic was a clinic or part of Community Health Center that particularly served smoking cessation counseling. The instrument used was by using questionnaires Dichotomous scale with criteria $\mathrm{O}=$ no smoking cessation clinic $; \mathbf{1}=$ smoking cessation clinic available.

\section{Data Analysis}

Statistics analysis by using Stata 13 program. In univariate analysis, sample characteristics with continuous data would be presented in parameter $\mathrm{n}$, mean, deviation standard, minimum, and maximum. Categorical data would be presented in $\mathrm{n}$ and percentage.

Bivariate analysis by using chi square test conducted toward each independent variable on individual level and community health center level to observe the respective effect toward tuberculosis recurrence. Variables with $\mathrm{p}<0.05$ would be input into multivariate model by using multiple logistic regression model. The effect of a variable was stated significant when the value of $\mathrm{p}<0.05$.

The effect of the individual variables would be analyzed by using multilevel analysis model with multilevel logistic regression model. Contextual effect of community health centers toward tuberculosis recurrence could be indicated by Intra-class Correlation Coefficient (ICC)

\section{Research Ethic}

The study was conducted with an approval from Health Research Ethics Committee of Dr. Moewardi Regional Hospital No. 1.388/XII/HREC/2019.

\section{RESULTS}

\section{A.Sample Characteristics}

The study was conducted toward 204 subjects who were divided into 17 community health centers. Sample characteristics for continuous and dichotomous variables were consecutively presented in Table 1 and 2.

The mean value of study subjects' age was 44.23 years old. The average subjects' income was $\operatorname{Rp} 2,230,490$. The mean value of weight gain was $4.5 \mathrm{~kg}$.

Dichotomous data indicated that study subjects were dominated by male and age group of 19-44 years. More than 50\% of study subjects earned income above city minimum wage. $16.67 \%$ study subjects were not BCG vaccinated.

Number of smokers and nonsmokers were almost comparable, however number of subjects who were nonsmoker were slightly higher than smoker. 80\% subjects were confirmed positive in initial bacteriological test and there were 107 people who gained weight $\geq 4.5 \mathrm{~kg}$ by the end of the treatment. The occurrences of chronic comorbidity in the form of DM or COPD were found in more than 15 subjects.

\section{B. The result of bivariate analysis}

Bivariate analysis was used to elaborate the effect of each independent variable toward dependent variable. The study used chi square with confident interval was 95\% $(\mathrm{p}<0.05)$. The result of bivariate analysis was presented in Table 3 .

Table 1. Sample characteristics (continuous data)

\begin{tabular}{llllll}
\hline Variables & n & Mean & SD & Min & Max \\
\hline Age (year) & 204 & 44.23 & 15.03 & 19 & 80 \\
Income (rupiah) & 204 & $2,230,490$ & 922,015 & 500,000 & $4,500,000$ \\
Weight gain (kg) & 204 & 4.50 & 2.29 & -2 & 14.7 \\
\hline
\end{tabular}


Muvida et al./ Do Community Health Centers Have Contextual Effect on

Table 2. Sample characteristics (dichotomous data)

\begin{tabular}{llcc}
\hline Variables & Criteria & $\begin{array}{c}\text { Frequency } \\
\text { (n) }\end{array}$ & $\begin{array}{c}\text { Percentage } \\
\text { (\%) }\end{array}$ \\
\hline Sex type & female & 75 & 36.76 \\
Age (year) & male & 129 & 63.24 \\
Income (rupiah) & $19-44$ & 105 & 51.47 \\
& $\geq 45$ & 99 & 48.53 \\
Education & $<1,800$, ooo & 64 & 31.37 \\
& $\geq 1,800$, ooo & 140 & 68.63 \\
& Non Elementary school & 107 & 52.45 \\
Graduates -Junior High & & \\
BCG vaccination history & School Graduates & & \\
Smoking history & High School Graduates- & 97 & 47.55 \\
Initial bacteriological test & Bachelor's Degree & & \\
& no & 34 & 16.67 \\
Weight gain (kg) & yes & 170 & 83.33 \\
& no & 105 & 51.47 \\
Diabetes mellitus & yes & 99 & 48.53 \\
COPD & negative & 26 & 12.75 \\
& positive & 178 & 87.25 \\
Recurrence & $<4.5$ & 97 & 47.55 \\
& $\geq 4.5$ & 107 & 52.45 \\
& no & 170 & 83.33 \\
& yes & 34 & 16.67 \\
& no & 173 & 84.80 \\
& yes & 31 & 15.20 \\
& Non recurrent & 158 & 77.45 \\
& recurrent & 46 & 22.55 \\
\hline
\end{tabular}

Male recurrent patients doubled the female. Recurrent risk on female increased by 1.12 times compared to female although it was not statistically significant. Positive result on initial bacteriological test is likely to increase recurrence risk. Population coverage that was less than 30,000 people and the existence of smoking cessation clinic in a Community Health Center decreased recurrence risk. However the significant effect was not found from the four variables.
In individual level, age $\geq 45$ years when began TB treatment, smoking history, the occurrence of chronic comorbidity in the form of DM and COPD increased the recurrence risk in the future. Income $\geq$ City Minimum Wage, minimum education was high school, BCG vaccination, weight gain $\geq 4.5 \mathrm{~kg}$ by the end of the treatment significantly contributed as the preventive factors toward TB recurrence. 
Muvida et al./ Do Community Health Centers Have Contextual Effect on

Table 3.Bivariate analysis of tuberculosis recurrence predictors

\begin{tabular}{|c|c|c|c|c|c|}
\hline Variables & $\begin{array}{l}\text { Non Recurrent } \\
\text { n (\%) }\end{array}$ & $\begin{array}{l}\text { Recurrent } \\
\text { n (\%) }\end{array}$ & $\begin{array}{l}\text { Total } \\
\text { n (\%) }\end{array}$ & OR & $\mathbf{p}$ \\
\hline \multicolumn{6}{|l|}{ Sex types } \\
\hline Female & $59(78.67)$ & $16(21.33)$ & 75 (100) & \multirow{2}{*}{1.12} & \multirow{2}{*}{0.751} \\
\hline Male & $99(76.74)$ & $30(23.26)$ & $129(100)$ & & \\
\hline \multicolumn{6}{|l|}{ Age (year) } \\
\hline $19-44$ & $90(85.71)$ & $15(14.29)$ & $105(100)$ & \multirow[t]{2}{*}{2.74} & \multirow[t]{2}{*}{0.004} \\
\hline$\geq 45$ & $68(68.69)$ & $31(31.31)$ & $99(100)$ & & \\
\hline \multicolumn{6}{|l|}{ Income (rupiah) } \\
\hline$<1,800,000$ & $36(56.25)$ & $28(43.75)$ & $64(100)$ & \multirow[t]{2}{*}{0.19} & \multirow[t]{2}{*}{$<0.001$} \\
\hline$\geq 1,800,000$ & $122(87.14)$ & $18(12.86)$ & $140(100)$ & & \\
\hline \multicolumn{6}{|l|}{ Ēucation } \\
\hline $\begin{array}{l}\text { Non elementary school } \\
\text { graduates - junior high school } \\
\text { graduates }\end{array}$ & $69(64.49)$ & $38(35.51)$ & $107(100)$ & \multirow[t]{2}{*}{0.16} & \multirow[t]{2}{*}{$<0.00$} \\
\hline $\begin{array}{l}\text { High school graduates - } \\
\text { bachelor's degree }\end{array}$ & $89(91.75)$ & $8(8.25)$ & $97(100)$ & & \\
\hline \multicolumn{6}{|l|}{ BCG vaccination history } \\
\hline No & $17(50.00)$ & $17(50.00)$ & \multirow[t]{2}{*}{34 (100) } & \multirow[t]{2}{*}{0.20} & \multirow[t]{2}{*}{$<0.00$} \\
\hline Yes & $141(82.94)$ & $29(17.06)$ & & & \\
\hline \multicolumn{6}{|l|}{ Smoking history } \\
\hline No & $89(84.76)$ & $16(15.24)$ & $105(100)$ & \multirow[t]{2}{*}{2.42} & \multirow[t]{2}{*}{0.010} \\
\hline Yes & $69(69.70)$ & $30(30.30)$ & $99(100)$ & & \\
\hline \multicolumn{6}{|l|}{ Initial bacteriological test } \\
\hline Negative & $22(84.62)$ & $4(15 \cdot 38)$ & $26(100)$ & \multirow[t]{2}{*}{1.70} & \multirow[t]{2}{*}{0.349} \\
\hline Positive & $136(76.40)$ & $42(23.60)$ & $178(100)$ & & \\
\hline \multicolumn{6}{|l|}{ Weight gain (kg) } \\
\hline$<4.5$ & $58(59.79)$ & $39(40.21)$ & $97(100)$ & 0.10 & $<0.001$ \\
\hline$\geq 4.5$ & $100(93.46)$ & $7(6.54)$ & $107(100)$ & & \\
\hline Diabetes mellitus & & & & & \\
\hline No & $142(83.53)$ & $28(16.47)$ & $170(100)$ & 5.70 & $<0.001$ \\
\hline Yes & $16(47.06)$ & $18(52.94)$ & $34(100)$ & & \\
\hline COPD & & & & & \\
\hline No & $144(83.24)$ & $29(16.76)$ & $173(100)$ & 6.03 & $<0.001$ \\
\hline Yes & $14(45.16)$ & $17(54.84)$ & $31(100)$ & & \\
\hline Population coverage & & & & & \\
\hline$<30,000$ & $65(77.38)$ & $19(22.62)$ & $84(100)$ & 0.99 & 0.984 \\
\hline$\geq 30,000$ & $93(77.50)$ & $27(22.50)$ & $120(100)$ & & \\
\hline Number of TB patients/mont & & & & & \\
\hline$<12$ & $100(83.33)$ & $20(16.67)$ & $120(100)$ & 2.24 & 0.016 \\
\hline$\geq 12$ & $58(69.05)$ & $26(30.95)$ & $84(100)$ & & \\
\hline Nüber of TB officers & & & & & \\
\hline$<4$ & $30(62.50)$ & $18(37.50)$ & $48(100)$ & 0.36 & 0.005 \\
\hline$\geq 4$ & $128(82.05)$ & $28(17.95)$ & $156(100)$ & & \\
\hline Ratio between TB officers/pa & ients & & & & \\
\hline$<0.6$ & $99(68.75)$ & $45(31.25)$ & $144(100)$ & 0.04 & $<0.001$ \\
\hline$\geq 0.6$ & $59(98.33)$ & $1(1.67)$ & $60(100)$ & & \\
\hline S̄̄moking cessation clinic & & & & & \\
\hline Not exist & $91(75.83)$ & $29(24.17)$ & $120(100)$ & 0.80 & 0.509 \\
\hline Exist & $67(79.76)$ & $17(20.24)$ & & & \\
\hline
\end{tabular}

Number of TB patients $\geq 12$ people/month was a recurrence risk factor in Community Health Center level. Number of TB officers $\geq 4$ and ratio of $\mathrm{TB}$ officers/patients $\geq 0.6$ decreased recurrence risk. The three variables were significant in bivariate analysis. 


\section{The result of Multilevel multiple logistic regression analysis}

Multilevel multiple logistic regression analysis was conducted to discover the effect of more than one independent variables toward dependent variables in individual level, also to calculate the effect of Community Health Centers in higher level toward the dependent variable. Independent variables that would be included in multivariate model were age, income, education, BCG vaccination history, smoking history, weight gain, DM and COPD.

Table 4. Multilevel multiple logistic regression analysis of tuberculosis recurrence predictors

\begin{tabular}{|c|c|c|c|c|}
\hline \multirow{2}{*}{ Tuberculosis Recurrence } & \multirow{2}{*}{$\mathbf{O R}$} & \multicolumn{2}{|c|}{$95 \% \mathrm{CI}$} & \multirow[b]{2}{*}{$\mathbf{p}$} \\
\hline & & Lower Limit & Upper Limit & \\
\hline \multicolumn{5}{|l|}{ Fixed effect level 1} \\
\hline Age (year) & 0.24 & 0.05 & 1.16 & 0.076 \\
\hline Income (rupiah) & 0.24 & 0.06 & 0.92 & 0.037 \\
\hline Education & 0.18 & 0.04 & 0.84 & 0.029 \\
\hline BCG Vaccination history & 0.11 & 0.02 & 0.67 & 0.017 \\
\hline Smoking history & 7.11 & 1.65 & 30.64 & 0.009 \\
\hline Weight gain (kg) & 0.06 & 0.01 & 0.28 & $<0.001$ \\
\hline Diabetes mellitus & 10.85 & 2.13 & 55.29 & 0.004 \\
\hline COPD & 4.77 & 0.83 & 27.45 & 0.080 \\
\hline \multicolumn{5}{|l|}{ Fixed effect level 2} \\
\hline Number of TB patients/month & 2.15 & 0.27 & 16.94 & 0.467 \\
\hline Number of TB officers & 0.45 & 0.05 & 4.19 & 0.482 \\
\hline Ratio of TB officers/ patients & 0.01 & $<0.01$ & 0.44 & 0.016 \\
\hline Constanta & 9.45 & 0.50 & 178.40 & 0.134 \\
\hline \multicolumn{5}{|l|}{ Random effect } \\
\hline \multicolumn{5}{|l|}{ Community Health Center } \\
\hline Var (constant) & 2.07 & 0.47 & 9.21 & \\
\hline \multicolumn{5}{|l|}{ Log likelihood $=-44.92$} \\
\hline LR test vs. logistic regression $p=0.003$ & & & & \\
\hline $\mathrm{ICC}=38.67 \%$ & & & & \\
\hline
\end{tabular}

Age group $\geq 45$ years at the initial TB treatment had 2.4 times recurrence risk compared to age group of 19-44 years in bivariate analysis. Subject with COPD has recurrence risk 4.77 times compared to subjects without COPD. However the effects were not statistically significant in multivariate model.

Odds of recurrence of subjects with income $\geq$ city minimum wage was 0.24 times compared to odds of subjects with income below city minimum wage. Subjects whose minimum education was High School had 0.18 times odds of recurrence compared to subjects with lower educational level. Subjects with BCG vaccination history had 0.11 times odds of recurrence compared to unvaccinated subjects. Subjects who were smoking had 7.11 times recurrence risk compared to nonsmokers. The effects were still statistically significant after being input into multivariate model.

Odds of recurrence in weight gain $\geq 4.5$ $\mathrm{kg}$ was 0.06 times compared to odds of recurrence in weight gain $<4.5 \mathrm{~kg}$. Subjects with DM had 10.85 times recurrence risk compared to subjects without DM. The effects were still statistically significant after being input into multivariate model.

Subjects who got treated in Community Health Centers which had TB patients $\geq 12 /$ month had 2.15 times recurrence risk compared to subjects who got treated in Community Health Centers with less patients. Subjects who got treated in Community Health Cen- 
ters which had TB control officers $\geq 4$ had 0.45 times odds of recurrence compare to subjects who got treated in Community Health Center with less TB control officers. However, the effect was no longer statistically significant after being input into multivariate model.

Subjects who got treated in Community Health Centers with ratio of TB officers/ patients $>0.6$ had 0.01 times odds recurrence compare to subjects who get treated in Community Health Center with lower ratio of TB officers/patients. The effect was still statistically significant after being input into multivariate model.

Community Health Centers had contextual effect toward tuberculosis. The result of intra-class correlation coefficient (ICC) was $38.67 \%$, it indicated that ratio of variety inter-groups toward total variety was $38.67 \%$.

\section{DISCUSSION}

1. The effect of sex types toward tuberculosis recurrence

Bivariate analysis indicated that male recurrent patients were doubled the female. Recurrence risk on male patients increased by 1.12 times compared to the female although it was statistically insignificant.

The result is in line with a study by Kim et al. (2016) and Moosazadeh et al. (2015) that indicates there is no significant difference between sex types toward tuberculosis recurrence although in general recurrence is more commonly suffered by male patients.

Jee et al. (2009) states that sex types contribute as effect modifier toward tuberculosis incidents and it represents the existence of higher dormant infection among males. In addition the large number of males who undergo recurrence also represents the existence of other behavioral factors directly related to tuberculosis recurrence, for example smoking (Velayutham et al., 2018).

\section{The effect of age toward tuberculo- sis recurrence}

In bivariate analysis, age group $\geq 45$ years old at the initial TB treatment had2.4 times higher recurrence risk compared to age group 1944 years. However the result turned to be statistically insignificant in multivariate mo$\operatorname{del}(\mathrm{OR}=0.24 ; 95 \% \mathrm{CI}=0.05$ up to $1.16 ; \mathrm{p}=$ o.076).

The result is in line with studies by Moosazadeh et al. (2015) and Luzze et al. (2013) which does not find significant difference of ages toward recurrent and non-recurrent groups. van der Heijden et al. (2018) gives an interesting description that might elaborate the inconsistence of the findings. Age affected tuberculosis recurrence in non-linear correlation. It could elaborate the result of other study which was statistically significant, that age group with highest risk for recurrence was not age group of more than 40 or 50 years old, instead age group of $25-55$ years old, because over the age recurrence risk is no longer increasing.

\section{The effect of income toward tuber- culosis recurrence}

Low income is included as one of the tuberculosis recurrence predictors. Recurrence risk is decreasing by $76 \%$ among subjects with income $\geq$ city minimum wage compared to subjects with lower income $(\mathrm{OR}=0.24$; $95 \% \mathrm{CI}=0.06$ up to $0.92 ; \mathrm{p}=0.037)$. The result is in line with the previous study that discovers low income is one of independent factors toward tuberculosis recurrent (Hung et al., 2015; Sun et al., 2017). Low income is often related with low nutritional status. Low economy status generates less decent environmental condition for the patients and also may bring up social susceptibility and reduced access to healthcare (WHO., 2019).

\section{The effect of education toward tuberculosis recurrence}

Lower education increased tuberculosis recurrence risk. Subjects whose minimum 
education was High School had 0.18 times higher odds of recurrence compared to subjects with lower education $(\mathrm{OR}=0.18$; 95\% $\mathrm{CI}=0.04$ up to $0.84 ; \mathrm{p}=0.029)$. Tuberculosis patients with lower education are likely to be recurrent faster compare to those who obtain higher education (Vieira et al., 2017).

\section{The effect of BCG vaccination his- tory toward tuberculosis recurren- ce}

The result of multivariate analysis indicated that BCG vaccination prevented tuberculosis recurrence. Subjects with BCG vaccination history had 0.11 times higher odds of recurrence compared to subjects who were not $\mathrm{BCG}$ vaccinated $(\mathrm{OR}=0.11 ; 95 \% \mathrm{CI} 0.02 \mathrm{up}$ to $0.67 ; \mathrm{p}=0.017$ ).

A study in England that studies the impact of BCG vaccine toward output of tuberculosis and discovers that BCG vaccine is related to the reduced mortality rate on tuberculosis patients although the benefit is decreasing in 10 years. BCG is also proven contributing as preventive factor by lowering down tuberculosis recurrence although the correlation is considered weak $(\mathrm{OR}=0.90$; 95\% CI= 0.81 up to $1.00 ; \mathrm{p}=0.056)$ (Abbott et al., 2019).

\section{The effect of smoking history to- ward tuberculosis recurrence}

Subjects who were smoking had 7.11 times higher recurrence risk compared to those who were not smoking. The effect was still statistically significant after being input into multivariate model $(\mathrm{OR}=7.11 ; 95 \% \mathrm{CI}=1.65$ up to $30.64 ; \mathrm{p}=0.009$ ).

Smokers have 2.2 times the risk to experience tuberculosis recurrence compare to nonsmokers (Moosazadeh et al., 2015). One of the important matters that should be notice is that smokers have longer time to transmit and can transmit M. tuberculosis to people who are in contact with them for longer period of time compare to nonsmokers. It starts prior diagnosis is established and continuous up to the beginning of therapy (Zellweger et al., 2014).

\section{The effect of initial bacteriological} test toward tuberculosis recurrence TB patients with positive result of initial bacteriological test were likely to recur compared to TB patients with negative result. However, the result was not statistically significant $(\mathrm{OR}=1.70 ; \mathrm{p}=0.349)$.

The study concerning the effect of initial bacteriological test toward tuberculosis recurrence still indicated inconsistent result. It is in line with a study by Maghradze et al. (2019) that includes variable of initial bacteriological test as one of tuberculosis recurrence predictors

Odds of recurrence for initial bacteriological test was 1.4 times. However, the result was not statistically significant $(\mathrm{OR}=1.40$; $95 \% \mathrm{CI}=0.2$ up to $9.8 ; \mathrm{p}=0.740$ ). the insignificant result is suspected because the size of sample is too small. It is proven by wide $95 \%$ CI.

\section{The effect of weight gain toward tu- berculosis recurrence}

Odds of recurrence for weight gain $\geq 4.5 \mathrm{~kg}$ was 0.06 times higher compared to odds of recurrence for weight gain $<4.5 \mathrm{~kg}(\mathrm{OR}=$ 0.06; 95\% $\mathrm{CI}=0.01$ up to 0.28 ; $\mathrm{p}<0.001$ ).

It is in accordance with the previous study. Weight gain $<3 \mathrm{~kg}$ after 2 months of induction phase therapy increases tuberculosis recurrent risk $(\mathrm{aHR}=1.9,95 \% \mathrm{CI}=1.3$ up to 2.6) (Luzze et al., 2013). Peetluk et al. (2019) indicates that for individual with negative HIV status, each $1 \mathrm{~kg}$ weight gain in the first 2 months of treatment will decrease therapy failure risk and recurrence by $12 \%$ $(\mathrm{HR}=0.88 ; 95 \% \mathrm{CI}=0.81$ up to 0.95$)$.

Weight loss of TB patients may be generated by several factors such as reduced food intake and metabolism change generated by diseases. Low body mass index and insufficient weight gain during TB treatment is related to increased mortality rate and recurren- 
ce and may become indication of TB severity, poor response to therapy, or the occurrence of comorbidity condition (WHO., 2013).

\section{The effect of diabetes mellitus to- ward tuberculosis recurrence}

The occurrence of comorbidity in the form of diabetes mellitus increased tuberculosis recurrence risk. Subjects with DM had 10.85 times higher risk to recur compared to subjects without $\mathrm{DM}(\mathrm{OR}=10.85 ; 95 \% \mathrm{CI}=2.13$ up to $55.29 ; \mathrm{p}=0.004)$. A study by Lee et al. (2014) and Hung et al. (2015) finds that the occurrence of diabetes condition increases tuberculosis recurrence risk by 1.51 to 1.96 times compares to without diabetes $(95 \% \mathrm{CI}=$ 1.02 up to 2.13). Diabetes condition affects immune response toward tuberculosis particularly because of chronic hyperglycemia condition. In addition to the commonly known effects of diabetes toward the occurrence of tuberculosis, there are also increasing evidences which indicate that diabetic comorbidity is also related to therapy failure, death and recurrence (Restrepo and Schlesinger., 2014).

Diabetes is often correlated with the lateness in cleansing tuberculosis germs during treatment (Jørgensen and Faurholt-Jepsen., 2014). Tuberculosis patients with diabetes are likely to endure conversion late-ness compare to non-diabetic tuberculosis patients. It is an initial predictor of therapy failure (positive sputum smear or culture in $\geq 5$ months of therapy) (Viswanathan et al., 2014).

10.The effect of COPD toward tuberculosis recurrence

Subjects with COPD had 4.77 times higher recurrence risk compared with subjects without COPD, although it was not statistically significant $(\mathrm{OR}=4.77 ; 95 \% \mathrm{CI}=0.83$ up to 27.45; $\mathrm{p}=0.080$ ). Being different from the study Moosazadeh et al. (2015) stated that COPD was one of the factors that increased tuberculosis recurrent risk $(\mathrm{OR}=1.59,95 \%$ $\mathrm{CI}=1.08$ up to 2.36 ).

Statistically insignificant result of multivariate analysis is very likely generated by COPD correlation with smoking. The significance of COPD correlation with recurrence is decreased after smoking variable is added into multivariate model.

In addition, less complete data is suspected becoming another cause of the finding. First, COPD history is not included in regular examination which is mentioned in TB01 Form. Second, clinical description of TB patients and COPD patients which is similar causes COPD presumption may get missed on patients with TB diagnosis. Most COPD patients are detected by using thorax imaging, however, since fast-molecular test is applied, thorax imaging is no longer a routine examination and may lead to unreported COPD.

\section{The effect of population coverage} toward tuberculosis recurrence

Population coverage which was less than 30,000 people within one Community Health Center reduced recurrence risk. However significant effect was not found in the variable.

It is in line with a study by Balgis et al. (2016) which states that ratio of Community Health Centers in each province does not affect the decrease of pulmonary tuberculosis prevalence. In other words, the number of population coverage is not directly related to pulmonary tuberculosis prevalence and its recurrence. It may happen because the number of Community Health Centers do not directly represent healthcare needs fulfillment and public access toward primary health care service in certain region.

\section{The effect of the number of TB patients/month toward tuberculo- sis recurrence}

Subjects who got treatment in Community Health Center with number of TB patients $\geq 12 /$ month had 2.15 times higher recurrence 
risk compared with subjects who got treatment in Community Health Centers with less patients. However, the effect was no longer significant after being input into multivariate model $(\mathrm{OR}=2.15 ; 95 \% \mathrm{CI}=0.27$ up to 16.94 ; $\mathrm{p}=0.467)$.

Chen et al. (2019) conducted multilevel study toward dormant tuberculosis infection among health workers in center for tuberculosis control and discovers that the number of tuberculosis patients in certain region is an institutional level factor that may affect dormant tuberculosis infection.

Higher level of epidemic is likely to bring up more recurrences. However, this variable does not actually indicate statistical significance so that the indicated correlation is an indirect correlation that may also get affected by the number of officers in a Community Health Center as well as the population density under the coverage of local Community Health Center.

\section{The effect of the number of TB officers toward tuberculosis recur- rence}

Subjects who got treatment in Community Health Centers with number of TB officers $\geq 4$ had 0.45 times higher odds of recurrence compared to subjects who got treatment in Community Health Centers with smaller number of TB officers although it was not statistically significant $(\mathrm{OR}=0.45 ; 95 \% \mathrm{CI}=$ 0.05 up to $4.19 ; \mathrm{p}=0.482$ ). TB officers are required to conduct education, monitoring, and visits to TB patients' home. If the number of TB officers is too small, the role cannot be performed optimally then the officers are likely to entrust the monitoring role to patients' family. Based on meta-analysis conducted by Alipanah et al. (2018), monitoring by family members possess higher level of therapy failure compares to direct monitoring by skilled officers.

Insignificant correlation in the study means the effect of the number of officers indirectly correlated with tuberculosis recurrence. The correlation also may get affected by the number of TB patients in local Community Health Center.

\section{The effect of ratio of TB officers/ patients toward tuberculosis re- currence}

Ratio of TB officers/ patients in each Community Health Center affects tuberculosis recurrence. Subjects who got treatment in community health centers with ratio of TB officers/ patients $\geq 0.6$ hado.o1 times higher odds of recurrence than subjects who got treatment in Community Health Centers with lower ratio of TB officers/patients $(\mathrm{OR}=0.01$; 95\% CI <0.01 up to $0.44 ; \mathrm{p}=0.016$ ).

TB officers have an important role in tuberculosis countermeasure. Griffiths et al. (2016) elaborates in a systematic review that high ratio of officers/patients increases patients' safety, care process, and performance of the officers themselves.

\section{The effect of smoking cessation cli- nics toward tuberculosis recur- rence}

The existence of smoking cessation clinics in Community Health Center reduced recurrence risk by $20 \%$ in bivariate analysis although it was not statistically significant $(\mathrm{OR}=0.80 ; \mathrm{p}=0.509)$. A systematic review by Whitehouse et al. (2018) states that additional intervention for smoking cessation in TB cases management effectively reduces patients' smoking habit during anti-tuberculosis treatment. The existence of smoking cessation clinic indirectly affects recurrence, however it affects tuberculosis patients' smoking behavior. It is suspected as the reason that makes the effect of smoking cessation clinic statistically insignificant.

\section{The effect of Community Health \\ Centers toward tuberculosis re- currence in the City of Surakarta}

The effect of fixed effect on the level of Community Health Centers has been explained 
separately. The result of analysis indicated that random effect of Community Health Centers with constant of variation of 2.07. The variation was relatively large compared with fixed effect constant of 9.45. The result $\mathrm{p}=0.003$ from LR test indicated that there was a significant difference between logistic regression model and multilevel model so that it can be concluded that multilevel model which has random coefficient gives better description.

Intra-class correlation coefficient (ICC) is a measurement that describes individual or unit level of similarities within the same group or institution (Murti, 2018). The result of ICC was $38.67 \%$ indicates that variation ratio was $38.67 \%$. It means $61.33 \%$ of recurrence can be explained with variables from individual level, and the rest can be explained by variables from Community Health Canter level. The value is higher than $10 \%$, indicates that the contextual effect of Community Health Centers cannot be ignored and it is important to conduct multilevel analysis.

Different facilities in each stratum of Community Health Center is suspected as one of the factors that contribute in random effect. A Community Health Center with higher stratum is likely to have better facilities and service quality. It generates decent output for tuberculosis patients. I may indirectly affect the range of recurrence rate afterward.

\section{AUTHOR CONTRIBUTION}

Muvida proposed the study idea, conducted coordination and all stages of the study, as well as complete the document of the study. Vitri Widyaningsih developed idea, study design, and hypothesis of the study. Bhisma Murti formulated study frame work, data processing, representing the result of study analysis, and preparing document of the study.

\section{CONFLICT OF INTEREST}

This study did not have any conflict of interests.

FUNDING AND SPONSORSHIP

The study was self-funded.

\section{ACKNOWLEDGEMENT}

We give the best gratitude to Research and Development Agency, Regional Development Planning Agency, and Health Office of Surakarta City which allow us to conduct the study. We also give our gratitude to Community Health Centers and tuberculosis control officers as well as all respondents that participated in the study.

\section{REFERENCE}

Abbott S, Christensen H, Lalor MK, Zenner D, Campbell C, Ramsay ME, Brookspollock E (2019). Exploring the effects of BCG vaccination in patients diagnosed with tuberculosis: Observational study using the Enhanced Tuberculosis Surveillance system. Vaccine, 37 (35): 5067-5072. doi: 10.1016/j.vaccine.2019.06.056.

Alipanah N, Jarlsberg L, Miller C, Linh NN, Falzon D, Jaramillo E, Nahid P (2018). Adherence interventions and outcomes of tuberculosis treatment: A systematic review and meta-analysis of trials and observational studies. PLoS ONE, 15 (7): e1002595. doi: 10.1371/journal.pmed.1002595.

Balgis, Panji FH, Hifli L (2016). The relationship between HIV incidence rate, district/municipality health budget, healthy house rate, and tuberculosis prevalence in Indonesia. J Epidemiol Public Health, 1 (3): 164-174. doi: 10.26911/jepublichealth.2016.01.03.03.

Chen B, Gu H, Wang X, Wang F, Peng Y, Ge E, Upshur R et al. (2019). Prevalence and determinants of latent tuberculosis 
infection among frontline tuberculosis healthcare workers in southeastern China : A multilevel analysis by individuals and health facilities. Int $J$ Infect Dis, 79: 26-33. doi: 10.1016/j.ijid.2018.11.010.

Davies GR, Wallis RS (2016). Methods for selecting regimen duration to prevent relapse in drug-susceptible and drug-resistant TB. Int $J$ Tuberc Lung Dis, 20(12): S13-S17. doi: 10.5588/ijtld.16.o231.

Griffiths P, Ball J, Drennan J, Dall'Ora C, Jones J, Maruotti A, Pope C, et al (2016). Nurse staffing and patient outcomes: Strengths and limitations of the evidence to inform policy and practice. A review and discussion paper based on evidence reviewed for the National Institute for Health and Care Excellence Safe Staffing guideline development. Int $\mathrm{J}$ Nurs Stud. doi: 10.1016/j.jjnurstu.2016.03.012.

Hox JJ (2010). Multilevel analysis: Techniques and applications. New York: Routledge.

Hung C, Chien J, Ou C (2015). Associated factors for tuberculosis recurrence in Taiwan: A nationwide nested case-control study from 1998 to 2010. PloS ONE, 10(5): e0124822. doi: 10.1371/journal.pone.0124822.

Jee SH, Golub JE, Jo J, Park IS, Ohrr H, Samet JM (2009). Original contribution smoking and risk of tuberculosis incidence, mortality, and recurrence in South Korean men and women. Am J Epidemiol, 170(12): 1478-1485. doi: 10.1093/aje/kwp3o8

Jørgensen ME, Faurholt-Jepsen D (2014). Is there an effect of glucose lowering treatment on incidence and prognosis of tuberculosis ? A systematic review. Curr Diab Rep, 14: 505. doi: 10.1007/s11892014-0505-1.

Ministry of Health (2011). Pedoman nasional pengendalian tuberkulosis. Jakarta: Kementerian Kesehatan RI.

Kim L, Moonan PK, Heilig CM, Woodruff RSY, Kammerer JS, Haddad MB (2016). Factors associated with recurrent tuberculosis more than 12 months after treatment completion. Int $\mathrm{J}$ Tuberc Lung Dis, 20 (1): 49-56. doi: 10.5588/ijtld.15.0442.

Lee P, Lin H, Huang AS, Wei S, Lai M, Lin H (2014). Diabetes and risk of tuberculosis relapse: nationwide nested case-control study. PLoS ONE, 9 (3): e92623. doi: 10.1371/journal.pone.0092623.

Luzze H, Johnson DF, Dickman K, Mayanja-Kizza H, Okwera A, Eisenach K, Cave MD, et al. (2013). Relapse more common than reinfection in recurrent tuberculosis 1-2 years post treatment in urban Uganda. Int $\mathrm{J}$ Tuberc Lung Dis, 17 (3): 361-367. doi: 10.5588/ijtld.11.0692.

Maghradze N, Jugheli L, Borrell S, Tukvadze $\mathrm{N}$ (2019). Classifying recurrent Mycobacterium tuberculosis cases in Georgia using MIRU- VNTR typing. PLoS ONE, 14 (10): e0223610. doi: 10.1371/journal.pone.0223610.

Moosazadeh M, Bahrampour A, Nasehi M, Khanjani N (2015). The incidence of recurrence of tuberculosis and its related factors in smear-positive pulmonary tuberculosis patients in Iran : A retrospective cohort study. Lung India, 32 (6): 557-56o. doi: 10.4103/0970-2113.168113.

Murti B (2018). Prinsip dan metode riset epidemiologi. Surakarta: Program Studi Ilmu Kesehatan Masyarakat Universitas Sebelas Maret.

Peetluk LS, Rebeiro PF, Cordeiro-Santos M, Kritski A, Andrade BB, Durovni B, Calvaca $S$, et al. (2019). Lack of weight gain during the first 2 months of treatment and human immunodeficiency virus 
Muvida et al./ Do Community Health Centers Have Contextual Effect on

independently predict unsuccessful treatment outcomes in tuberculosis. $\mathrm{J}$ Infect Dis. doi: 10.1093/infdis/jiz595.

Perhimpunan Dokter Paru Indonesia (2011). Tuberkulosis: Pedoman Diagnosis dan Penatalaksanaan di Indonesia. Jakarta: Indah Offset Citra Grafika.

Restrepo BI, Schlesinger LS (2014). Impact of diabetes on the natural history of tuberculosis. Diabetes Res Clin Pract, 106 (2): 191-199. doi: 10.1016/j.diabres.2014.06.011.

Sotgiu G, Centis R, Migliori GB (2016). Tuberculosis management and determinants of recurrence. IJTLD, 20 (1): 3. doi: 10.5588/ijtld.15.090.

Sulis G, Roggi A, Matteelli A, Raviglione MC (2014). Tuberculosis: epidemiology and control. Mediterr J Hematol Infect Dis, 6(1): e2014070. doi: 10.4084/MJHID.2014.070.

Sun Y, Harley D, Vally H, Sleigh A (2017). Impact of multidrug resistance on tuberculosis recurrence and long-term outcome in China. PLoS ONE, 12 (1): e0168865. doi: 10.1371/journal.pone.0168865 .

van der Heijden YF, Karim F, Chinappa T, Mufamadi G, Zako L, Shepherd BE, Maruri F, et al (2018). Older age at first tuberculosis diagnosis is associated with tuberculosis recurrence in HIVnegative persons. Int $J$ Tuberc Lung Dis, 22 (8): 871-877. doi: 10.5588/ijtld.17.0766.Older.

Velayutham B, Chadha VK, Singla N, Narang P, Rao VG, Nair S, Ramalingam S (2018). Recurrence of tuberculosis among newly diagnosed sputum positive pulmonary tuberculosis patients treated under the Revised National Tuberculosis Control Programme, India : A multi-centric prospective study. PLoS ONE, 13 (7): 150-200. doi: 10.1371/journal. pone.0200150.

Vieira AA, Leite DT, Adreoni S (2017). Tuberculosis recurrence in a priority city in the state of São Paulo, Brazil. J Bras Pneumol, 43(2): 106-112. doi: 10.1590/S1806-37562016000000002.

Viswanathan V, Vigneswari A, Selvan K, Satyavani K, Rajeswari R, Kapur A (2014). Effect of diabetes on treatment outcome of smear positive pulmonary tuberculosis: A report from South India. J Diabetes Complicat, 28(2): 162-165. doi: 10.1016/j.jdiacomp.2013.12.003.

Whitehouse E, Lai J, Golub JE, Farley JE (2018). A systematic review of the effectiveness of smoking cessation interventions among patients with tuberculosis. Public Health Action, 8(2): 3749. doi: 10.5588/pha.18.00o6.

WHO (2013). Guideline: Nutritional care and support for patients with tuberculosis. Geneva: World Health Organization.

WHO (2018a). Tuberculosis. Retrieved from https://www.who.int/news-room/factsheets/detail/tuberculosis.

WHO (2018b). Global Tuberculosis Report. Geneva: World Health Organization.

WHO (2019). Ten threats to global health in 2019. https://www.who.int/emergencies/ten-threats-to-global-health-in-2019.

Zellweger J, Cattamanchi A, Sotgiu G (2015).

Tobacco and tuberculosis: could we improve tuberculosis outcomes by helping patients to stop smoking? Eur Respir J, 45: 583-585. doi: 10.1183/09031936.00221814 . 